Provided for non-commercial research and education use. Not for reproduction, distribution or commercial use.

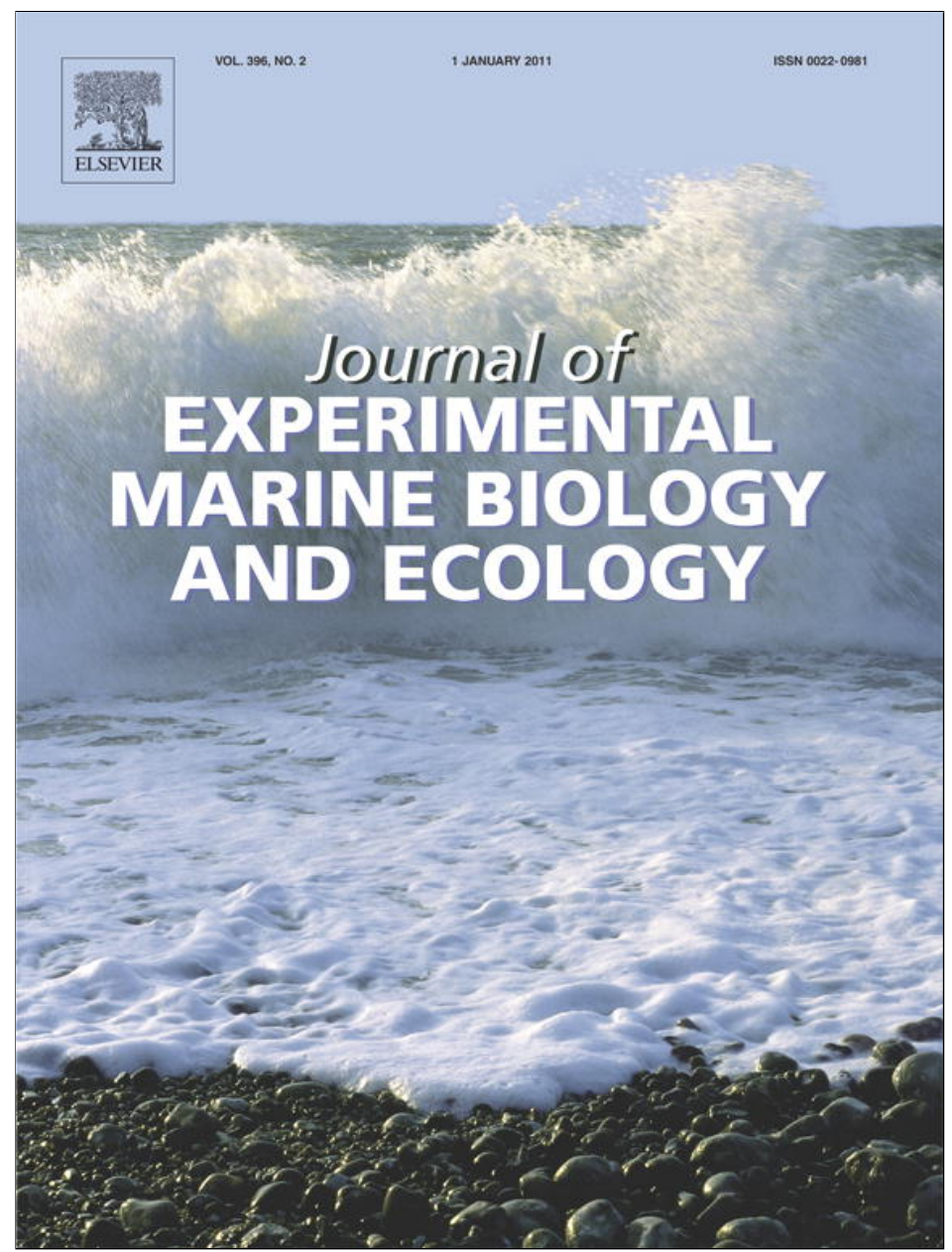

(This is a sample cover image for this issue. The actual cover is not yet available at this time.)

This article appeared in a journal published by Elsevier. The attached copy is furnished to the author for internal non-commercial research and education use, including for instruction at the authors institution and sharing with colleagues.

Other uses, including reproduction and distribution, or selling or licensing copies, or posting to personal, institutional or third party websites are prohibited.

In most cases authors are permitted to post their version of the article (e.g. in Word or Tex form) to their personal website or institutional repository. Authors requiring further information regarding Elsevier's archiving and manuscript policies are encouraged to visit:

http://www.elsevier.com/copyright 


\title{
Cultivating endosymbionts - Host environmental mimics support the survival of Symbiodinium C15 ex hospite
}

\author{
Thomas Krueger ${ }^{\mathrm{a}, \mathrm{b}, *}$, Ruth D. Gates ${ }^{\mathrm{a}}$ \\ ${ }^{a}$ Hawai'i Institute of Marine Biology, P.O. Box 1346, Kāne'ohe, HI, USA \\ b School of Biological Sciences, Victoria University of Wellington, P.O. Box 600, Wellington 6140, New Zealand
}

\section{A R T I C L E I N F O}

\section{Article history:}

Received 28 August 2011

Received in revised form 4 December 2011

Accepted 5 December 2011

Available online $\mathrm{xxxx}$

\section{Keywords:}

Cnidaria

Cultivation

Dinoflagellate

Host factor

Symbiosis

Vertical transmission

\begin{abstract}
A B S T R A C T
Sustaining in vitro cultures of endosymbiotic dinoflagellates in the genus Symbiodinium is important, addressing questions relating to Symbiodinium function and Symbiodinium dependent host fitness. Difficulties in establishing representative Symbiodinium cultures from Pacific coral isolates limit the availability of diverse Symbiodinium types, especially in the C clade. While this clade exhibits high subcladal diversity (over 100 types), and represents the ecologically dominating phylotype in Indo-Pacific corals, only two ancestral types $\mathrm{C} 1$ and $\mathrm{C} 3$ are currently in permanent culture. This study attempted to cultivate Symbiodinium C15, a derived $\mathrm{C}$ clade type, from the Hawaiian coral Porites compressa. We tested a number of basic media in combination with defined organic supplements, as well as host factor derived additives and ion-manipulated media, in order to mimic the intracellular ion regime of a zooxanthellate host. While basic media did not support cell survival at all, the use of organic supplements such as amino acids plus taurine or host derived tissue homogenate had a positive effect on survival and stabilized in vitro densities temporarily. However, none of the conditions tested supported a proliferating motile Symbiodinium C15 culture. In two independent experiments, a potentially free-living Symbiodinium A clade strain was successfully cultured, which exhibited phylogenetic separation from endosymbiotic A clade strains. This study demonstrates the effectiveness of host mimics or host derived supplements to study otherwise 'unculturable' Symbiodinium strains. Our results imply that Symbiodinium C15 is incapable of surviving ex hospite unless a host-derived or potential host mimicking feature is present. This potential host dependency has important implications for post-bleaching recovery of the endemic coral $P$. compressa and suggests a coevolutionary link between vertical transmission mode, host dependency of the symbiont and bleaching resistance of this holobiont.
\end{abstract}

(c) 2011 Elsevier B.V. All rights reserved.

\section{Introduction}

Scleractinian hermatypic corals form obligate endosymbiotic associations with dinoflagellates in the genus Symbiodinium. These interactions contextualize the ecological success of coral reefs, with newly fixed photosynthates being translocated from Symbiodinium to the host, and endosymbionts that thrive on host-derived inorganic compounds in otherwise nutrient-poor tropical waters (Muscatine and Hand, 1958). Although best known for their association with corals, Symbiodinium spp. also associates with some species of anemones, jellyfish, tridacnid bivalves, flatworms, sponges, nudibranchs or protozoa such as foraminiferans and ciliates (reviewed in Stat et al., 2006).

Symbiodinium spp. were originally grouped with other 'yellow' symbionts and described by the term zooxanthellae, however, their cultivation and identification as gymnoid dinoflagellates led to the

* Corresponding author at : School of Biological Sciences, Victoria University of Wellington, P.O. Box 600, Wellington 6140, New Zealand. Tel.: + 644463 5233x8098.

E-mail address: thomas.krueger@vuw.ac.nz (T. Krueger). first comprehensive description and novel classification as Symbiodinium microadriaticum sp. nov. by Freudenthal (1962). Since then, a number of studies have described variability in cellular ultrastructure, morphology, physiological features and host infectivity in the genus Symbiodinium (reviewed in Coffroth and Santos, 2005; LaJeunesse, 2001). Through the application of molecular techniques, a phylogenetic framework for Symbiodinium, based on the 18S-rDNA and faster evolving internal transcribed spacer regions (ITS1 and ITS2) was established (Lajeunesse, 2001). As result the genus Symbiodinium is now known to contain nine major lineages (clades A-I) that each contain numerous subtypes (Pochon and Gates, 2010). In combination with biogeographical and ecological data, evolutionary models that illustrate the processes of genetic radiation and host specialization within the genus have been proposed (Lajeunesse, 2005; Pochon et al., 2006).

Symbiodinium clade $\mathrm{C}$ is ecologically dominant in Indo-Pacific corals and with clade $\mathrm{B}$ is also the most common type in the Atlantic-Caribbean region (reviewed in LaJeunesse, 2005). Despite the number of in vitro Symbiodinium cultures in collections worldwide, almost no clade $\mathrm{C}$ cultures exist, though the subcladal diversity in 
this lineage is the largest among the clades (Correa and Baker, 2009; LaJeunesse et al., 2004, 2010; Pochon et al., 2006; Stat et al., 2008a). The $\mathrm{C}$ clade isolates currently in culture represent the most ancestral members of this clade, ITS2-types C1 and C3, types that are endosymbionts in a broad diversity of cnidarian hosts and possess a broad geographic range. To our knowledge, none of the more derived C clade Symbiodinium types have yet been successfully cultured. Difficulties in establishing cultures and problems associated with differential cultivation success for certain Symbiodinium types have been reported in the literature (Carlos et al., 1999; Santos et al., 2001). In fact, it has been illustrated that factors like clade-dependent spatial segregation or differential growth in the presence of antibiotics occur in mixed cultures and can lead to non-representative cultivation of types from fresh isolates (Santos et al., 2001).

The coral holobiont represents a physiological chimera whose response to environmental stress reflects performance limits set by both the animal and Symbiodinium partners as well as their interactive physiology. To understand these limits, physiological parameters specific to each partner, as well as the functionality and integration of their association need to be assessed under defined and controlled conditions. As such, the establishment of in vitro Symbiodinium cultures represents one of the fundamental prerequisites for studies that address these questions. In this context, the association with the scleractinian coral Porites sp. is of particular interest, since the holobiont expresses high bleaching resistance and ecological robustness (Loya et al., 2001; Stimson et al., 2002). In the Indo-Pacific, Porites sp. generally associates with Symbiodinium clade C ITS2 types known as C15-cluster (LaJeunesse, 2005; Stat et al., 2009b), and in the East-Pacific/Caribbean with C45- and C57-cluster (including C66 variants) (Correa and Baker, 2009; Lajeunesse, 2005; Lajeunesse et al., 2008). Since the C15- and C45-cluster in Porites associations experienced separate evolutionary radiation in the Indo-Pacific and Atlantic-Caribbean, both have been viewed as evolutionary successful (Lajeunesse, 2005). Rare associations with non-poritid coral hosts such as Acropora sp. and Montipora sp. in the Great Barrier Reef (GBR) and Thailand (Lajeunesse, 2005; LaJeunesse et al., 2010), Pocillopora damicornis in Kenya (Visram and Douglas, 2006) as well as some octocorals in the GBR and Sarcothelia sp. in Hawai'i (reviewed in Goulet et al., 2008b) have been described. There is evidence that the thermal stress resistance of a Porites-C15 holobiont might be a result of high physiological capacities (e.g., antioxidative system, heat shock proteins) in both, the host and its symbiont (Barshis et al., 2010; Fisher, 2006; Fitt et al., 2009). Furthermore, field studies in the Indo-Pacific have shown that Porites-C15 associations are stable over broad geographical ranges and temperature gradients as well as through bleaching events or after transplantation (Goulet et al., 2008a; LaJeunesse et al., 2004; Stat et al., 2008a, 2009a).

To build the capacity to facilitate such investigations as it pertains to Porites-Symbiodinium associations, we attempted to establish a new culture of Symbiodinium C15 from the Hawaiian coral host Porites compressa Dana, 1846. Our approach was to examine common culture media as well as media that encompass organic features found in the symbiont's intracellular environment. To accomplish this we tested a broad range of basic cultivation media with and without organic supplements such as glycerol, coral-derived homogenates, a synthetic host factor as well as a medium modified to mimic the internal ionic composition of a zooxanthellate host. We failed to establish a persistent dividing culture but we were able to maintain C15 cells in media spiked with host homogenate or a synthetic host factor. Symbiodinium C15 in P. compressa is passed from one generation to the next via maternal transmission and we hypothesize that our failure to establish a successful culture results from this coevolutionary linkage between host and symbiont type. Our results suggest however, that organic supplements in culture media can facilitate the cultivation of symbiotic strains that are otherwise unculturable.

\section{Material and methods}

\subsection{Culture preparation and maintenance}

Samples of the hermatypic scleractinian coral $P$. compressa were collected from the reef adjacent to Coconut Island in Kāne'ohe Bay $\left(21^{\circ} 26.2^{\prime} \mathrm{N}, 157^{\circ} 47.6^{\prime} \mathrm{W}\right)$, O'ahu, Hawai'i between April and September 2009. Coral pieces were briefly rinsed and water picked using filtered synthetic seawater (SSW, Instant Ocean sea salt, Spectrum Brands, Inc., Atlanta, GA, USA). Larger mucus agglomerates were dissolved using a syringe or a glass homogenizer. Cells were washed by cycles of centrifugation and resuspension in either filtered SSW or respective medium ( 4 cycles of $700 \times g$ for 5 min at room temperature). For some experiments, cells were incubated for $24 \mathrm{~h}$ in $0.2 \mu \mathrm{m}$ filtered antibiotics (Polne-Fuller, 1991) in SSW prior to the experiment. Cell densities were determined based on hemocytometer counts $(n=4)$ under the light microscope (System microscope BX51, Olympus). Cell sizes of freshly isolated cells $(n=50)$ were determined according to microscopic photographs with scale bar (Optronics MacroFire camera model \#45726391 using the software PictureFrame), employing the software Image $1.42 \mathrm{k}$ (Open Source, National Institute of Health, MD, USA).

Cultures were grown in $250 \mathrm{~mL}$ Erlenmeyer flasks or $10 \times 75 \mathrm{~mm}$ borosilicate culture tubes (Fisher Scientific) at $25^{\circ} \mathrm{C}$ on a constant $12 \mathrm{~h} \mathrm{~L}: 12 \mathrm{~h} \mathrm{D}$ cycle in an air-circulated incubator (I36LLX Controlled Environment Chamber, Percival Scientific Inc. Perry, IA, USA). Light levels were adjusted to $120-130 \mu \mathrm{mol} \mathrm{m}^{-2} \mathrm{~s}^{-1}$ and $70-80 \mu \mathrm{mol} \mathrm{m}^{-2} \mathrm{~s}^{-1}$, respectively (measured with QSL-100 spherical sensor Biospherical Instruments Inc., San Diego, CA, USA and QMSW-SS cosine sensor, Apogee Instruments Inc., Roseville, CA, USA, respectively). The latter intensities were applied in order to account for differences between a spherical and cosine corrected light sensor, assuming that minor differences in light levels might not be crucial for the general cultivation success.

\subsection{Media preparation and specifications}

Based on the maintenance conditions for Symbiodinium clade C isolates at CSIRO in Hobart (Australia), CCMP in West Boothbay Harbor (USA), the BURR culture collection in Buffalo (USA) and the Santos Lab culture collection in Auburn (USA), four media were chosen and tested for their suitability as culture medium for Symbiodinium C15. The composition and preparation of these culture media were based on formulas given in Andersen et al. (2005) for f/2-, L1- and K-medium and Blank (1987) for ASP-8A-medium. These media differ primarily with respect to nitrogen source $\left(\mathrm{NO}_{3}^{-} / \mathrm{NH}_{4}^{+}\right)$, amount of chelating agents and their combination of trace elements and organic supplements. Silica and Tris-base were omitted from all media and the final $\mathrm{pH}$ adjusted to 8.0. We refer in the following to all four media as silica free media. All used glasswares (incubation flasks, tubing, bottles) were washed in $0.1 \mathrm{M} \mathrm{HCl}$ and then soaked and rinsed in distilled water. All incubation vessels were autoclaved prior to use.

Basic media were tested with and without active aeration $(0.2 \mu \mathrm{m}$ PTFE membrane filtered air), as half-concentrated media as well as in form of solid agar plates $(1 \% \mathrm{w} / \mathrm{v})$. Furthermore due to contamination with different microalgae in some trials, a serial dilution of the fresh Symbiodinium isolate in basic media was tested. Agar plates were prepared by dissolving agar in SSW or distilled water (in case of ASP-8A) and autoclaved. Double-concentrated filter-sterilized media and $10 \times$ antibiotics were pre-warmed to $50-55^{\circ} \mathrm{C}$ and mixed with autoclaved agar under sterile conditions and plates poured.

Apart from the basic media trials, a number of supplements were tested for growth stimulation (Table 1). Based on the concept of Erd-Schreiber media, autoclaved coral rubble $(20-50 \mathrm{~g}$ per $250 \mathrm{~mL}$ flask), wet sea sediment $(\sim 100 \mathrm{~g})$ or red soil of Coconut Island $(\sim 70 \mathrm{~g})$ were tested as additives to all basic media. In addition, they 
Table 1

Summary of experiments conducted. Number in brackets indicate repeated experiments. Light intensities measured as photosynthetically active radiation (PAR, 400-700 nm). SSW $=$ Synthetic seawater; $\mathrm{HH}=$ Host homogenate derived from Porites compressa (HHu: untreated; HHc: centrifuged; HHf: filter-sterilized as described in the text); TSP $=$ Total soluble protein concentration as determined after Bradford (1976).

\begin{tabular}{|c|c|c|c|c|}
\hline Trial & Media specifications & Culture incubation & $\begin{array}{l}24 \mathrm{~h} \text { antibiotic } \\
\text { treatment after } \\
\text { isolation }\end{array}$ & Duration \\
\hline $\begin{array}{l}\text { Basic media } \\
\text { - Active vs. } \\
\text { passive aeration }\end{array}$ & L1-, f/2-, K-, ASP-8A-medium & $\begin{array}{l}\text { Erlenmeyer flask; } 125 \mathrm{~mL} \text {; } \\
120-130 \mu \mathrm{mol} \mathrm{m}^{-2} \mathrm{~s}^{-1} \text {; active and passive } \\
\text { aeration }\end{array}$ & No & $\begin{array}{l}10 \text { days, final } \\
\text { examination on day } \\
14\end{array}$ \\
\hline $\begin{array}{l}\text { Basic media } \\
\text { - Incubation on } \\
\text { agar }\end{array}$ & L1-, f/2-, K-, ASP-8A-medium & $\begin{array}{l}\text { Dilution streak on solid agar plates; } \\
120-130 \mu \mathrm{mol} \mathrm{m} \mathrm{m}^{-2} \mathrm{~s}^{-1}\end{array}$ & $\begin{array}{l}\text { No; antibiotics } \\
\text { in agar }\end{array}$ & 31 days \\
\hline $\begin{array}{l}\text { Basic media } \\
\text { - Half vs. full } \\
\text { concentrated }\end{array}$ & $\begin{array}{l}\text { L1-, f/2-, K-medium; full vs. half concentrated media, } \\
\text { active aeration }\end{array}$ & $\begin{array}{l}\text { Erlenmeyer flask; } 125 \mathrm{~mL} \text {; } \\
120-130 \mu \mathrm{mol} \mathrm{m} \mathrm{m}^{-2} \mathrm{~s}^{-1} \text {; active aeration }\end{array}$ & No & $\begin{array}{l}6 \text { days, final } \\
\text { examination on day } \\
14\end{array}$ \\
\hline $\begin{array}{l}\text { Undefined } \\
\text { supplement }\end{array}$ & $\begin{array}{l}\text { L1-, f/2-, K-, ASP-8A-medium supplemented with } \\
\text { autoclaved soil, sediment, coral rubble, passive aeration }\end{array}$ & $\begin{array}{l}\text { Erlenmeyer flask; } 125 \mathrm{~mL} \text {; } \\
120-130 \mu \mathrm{mol} \mathrm{m}{ }^{-2} \mathrm{~s}^{-1}\end{array}$ & No & 28 days \\
\hline $\begin{array}{l}\text { Glycerol } \\
\text { supplement }(2 \times)\end{array}$ & $\begin{array}{l}\text { L1-, f/2-, K-medium supplemented with glycerol ( } 50 \mathrm{mM} \\
\text { and } 100 \mathrm{mM} \text { ) }\end{array}$ & Culture tube; $3 \mathrm{~mL} ; 120-130 \mu \mathrm{mol} \mathrm{m}{ }^{-2} \mathrm{~s}^{-1}$ & Yes + no & 12 days +21 days \\
\hline $\begin{array}{l}\text { Amino acids + taurine } \\
\text { supplement }(2 \times)\end{array}$ & $\begin{array}{l}\text { L1-, f/2-, K-medium supplemented with modified synthetic } \\
\text { host factor (Gates et al., 1995; final concentration } 92 \mathrm{mM} \text { ) }\end{array}$ & Culture tube; $3 \mathrm{~mL} ; 120-130 \mu \mathrm{mol} \mathrm{m}^{-2} \mathrm{~s}^{-1}$ & No + yes & 29 days +14 days \\
\hline $\begin{array}{l}\text { Host homogenate } \\
\text { supplement }(2 \times)\end{array}$ & HHc in SSW and HHf in L1-medium (TSP: $5.8 \pm 0.4 \mu \mathrm{g} / \mathrm{mL}$ ) & Culture tube; $3 \mathrm{~mL} ; 120-130 \mu \mathrm{mol} \mathrm{m}{ }^{-2} \mathrm{~s}^{-1}$ & Yes + no & 8 days +12 days \\
\hline $\begin{array}{l}\text { Host homogenate } \\
\text { supplement } \\
\text { - Transition } \\
\text { experiment }\end{array}$ & $\begin{array}{l}\text { HHu in SSW; transition into HHf-enriched L1-, f/2- and K- } \\
\text { medium }\end{array}$ & Culture tube; $3 \mathrm{~mL} ; 120-130 \mu \mathrm{mol} \mathrm{m}{ }^{-2} \mathrm{~s}^{-1}$ & No & 24 days \\
\hline $\begin{array}{l}\text { Host homogenate } \\
\text { supplement } \\
\text { - Incubation on agar }\end{array}$ & $\begin{array}{l}\text { HHf in L1-medium (TSP: } ~ 28 \mu \mathrm{g} / \mathrm{mL} \text { ); HHu in SSW } \\
\text { (TSP: } 60.5 \pm 4.7 \mu \mathrm{g} / \mathrm{mL} \text { ) }\end{array}$ & $\begin{array}{l}\text { Plating of } 100 \mu \mathrm{L} \text { on solid agar plates; } \\
70-80 \mu \mathrm{mol} \mathrm{m} \mathrm{m}^{-2} \mathrm{~s}^{-1}\end{array}$ & $\begin{array}{l}\text { No; antibiotics } \\
\text { in agar }\end{array}$ & $\begin{array}{l}29 \text { days }(\mathrm{HHf}) \\
+68 \text { days }(\mathrm{HHu})\end{array}$ \\
\hline $\begin{array}{l}\text { Modified ASP-8A- } \\
\text { medium }\end{array}$ & $\begin{array}{l}\text { ASP-8A-medium modified according to Seibt and Schlichter } \\
\text { (2001); pure medium and medium plus BSA }(1.0,0.1,0.01 \\
\mathrm{mg} / \mathrm{mL} \text { ) or HHc (TSP: } 112.9 \pm 2.6 \mu \mathrm{g} / \mathrm{mL})\end{array}$ & Culture tube; $3 \mathrm{~mL} ; 70-80 \mu \mathrm{mol} \mathrm{m}{ }^{-2} \mathrm{~s}^{-1}$ & Yes & 9 days \\
\hline
\end{tabular}

were supplemented with organic additives such as glycerol (50 and $100 \mathrm{mM}$ final concentration), an amino acid plus taurine mixture and a host derived diluted tissue homogenate. Glycerol supplement stock solutions were prepared in SSW, filter-sterilized and $\mathrm{pH}$ adjusted to 8.0. The amino acid supplement was based on the 'synthetic host factor' derived from P. damicornis (Gates et al., 1995). Individual concentrations were chosen as mean of the percentage of each compound in the two coral colonies originally investigated. $\beta$-glutamic acid was omitted, but alanine $(16.24 \mathrm{mM})$, arginine $(3.28 \mathrm{mM})$, asparagine $(1 \mathrm{mM})$, aspartic acid $(1.93 \mathrm{mM})$, glutamic acid $(23.64 \mathrm{mM})$, glycine $(11.12 \mathrm{mM})$, histidine $(1.44 \mathrm{mM})$, isoleucine $(4.54 \mathrm{mM})$, leucine $(3.79 \mathrm{mM})$, methionine $(2.69 \mathrm{mM})$, phenylalanine $(3.62 \mathrm{mM})$, serine $(2.82 \mathrm{mM})$, tyrosine $(1.51 \mathrm{mM})$, valine $(9.24 \mathrm{mM})$ and taurine $(4.88 \mathrm{mM})$ included. The final concentration of this supplement was $92 \mathrm{mM}$. All compounds were prepared in SSW, filter-sterilized, stored at $4{ }^{\circ} \mathrm{C}$ in the dark and used within two weeks of preparation. A raw host homogenate from $P$. compressa was also tested. Here we use the term host homogenate to describe the first wash supernatant that contains the lysed $P$. compressa tissue in seawater. Host homogenate was used as untreated, centrifuged $\left(16,000 \times \mathrm{g}, 5 \mathrm{~min}, 4^{\circ} \mathrm{C}\right)$ and filter-sterilized $(0.2 \mu \mathrm{m})$ supplement (Table 1). Total soluble protein concentration (TSP) was determined for some trials after Bradford (1976). Based on studies on transient sodium stress in Symbiodinium after isolation from their host (Seibt and Schlichter, 2001 and references therein), an altered formula of ASP-8A-medium was developed and tested. ASP-8A-medium was chosen because its base is distilled water, which makes it suitable for ion manipulation. The medium was modified in order to mimic the internal ionic composition of a zooxanthellate host's cytoplasm (anemone Anemonia sulcata). The osmolarity of this isoionic medium was adjusted to SSW osmolarity by adding mannitol (final osmolarity for modified ASP-8A: $1008 \mathrm{mmol} / \mathrm{kg}$; SSW: $1028 \mathrm{mmol} /$ $\mathrm{kg}$ determined with a Vapro Pressure Osmometer Model 5520; Wescor Inc., Logan, UT, USA) and final pH adjusted to 8.0. Final concentrations were $140.1 \mathrm{mM}$ (potassium), $150.8 \mathrm{mM}$ (sodium),
$25 \mathrm{mM}$ (magnesium), $5 \mathrm{mM}$ (calcium) and $295 \mathrm{mM}$ (chloride). Isolated Symbiodinium cells were incubated in modified ASP-8A-medium (ASP-8 $\mathrm{A}_{\mathrm{mod}}$ ) as well as in bovine serum albumin and host homogenate supplemented ASP- $8 \mathrm{~A}_{\text {mod }}$-medium (BSA with final concentrations of $1.00,0.10$ and $0.01 \mathrm{mg} / \mathrm{mL}$ ).

\subsection{Genotyping}

Fresh isolates and final cultures of Symbiodinium were genotyped to verify their cladal identity based on the internal transcribed spacer 2 region (ITS2) of the nuclear ribosomal RNA (Lajeunesse, 2001). DNA extraction, ITS2 PCR amplification, cloning and sequencing were performed according to previously published procedures (Stat et al., 2009b) using the forward primer itsD ( $5^{\prime}$-GTGAATTGCAGAACTCCGTG-3') and reverse primer its2rev2 (5'-CCTCCGCCTACTTATATGCTT-3'). Amplicons were sequenced at the University of Hawai'i Sequencing Facility.

Retrieved sequences were identified, employing the Basic Local Alignment Search Tool (BLAST) for nucleotide sequences (blastn) of the National Center for Biotechnology Information's (NCBI) BLAST database as well as the internal Symbiodinium sequence database of the Gates Lab at HIMB. Additional ITS2-sequences for analyses of phylogenetic relatedness of detected Symbiodinium strains in this study were retrieved from GenBank. Sequences for symbiotic A clade members (A1, A3, A4, A6, A7, A8, A10, A11, A12, A13, A15a, A16; GenBank accession nos. AF333505, AF333507, AF333509, AF186058, AY239360, AY258468, EU792882, EU449041, EU792883, AF333504, EU792884, EU792888) as well as free-living Symbiodinium sequences from Okinawa (Oku05, Oku09, Oku11, Oku12, Oku17; GenBank accession nos. EU106355, EU106358, EU106360, EU106361, EU106364, from Hirose et al., 2008) and Hawai'i (HA3-5; GenBank accession no. AF184948 from Carlos et al., 1999) were included. ITS2-sequences of the dinoflagellates Gymnodinium simplex (GenBank accession no. AY686651) and Polarella glacialis (GenBank accession no. EU445333) were used as out-groups. Obtained sample sequences and reference sequences (total 33 sequences) obtained from GenBank 
were aligned and overhangs removed. Phylogenetic analysis was performed in Geneious Pro 4.8.2 (Biomatters Ltd.) using PhyML v2.4.5 (Guindon and Gascuel, 2003) for tree generation. Tree topology was determined using the Maximum Likelihood (ML) method with a bootstrap analysis (100 replicates) to infer tree topology robustness (Hillis and Bull, 1993). A GTR substitution model (discrete gamma) with four substitution rate categories and program estimated values for all other parameters was chosen. The initial tree was obtained via BIONJ (Gascuel, 1997). GTR model specifications: Likelihood: Loglk $=-1507.7336$; Proportion of invariable sites: 0.000; Relative rate parameters: $\mathrm{A} \leftrightarrow \mathrm{C}: 0.9950, \mathrm{~A} \leftrightarrow \mathrm{G}: 2.9370, \mathrm{~A} \leftrightarrow \mathrm{T}: 1.1890$, $\mathrm{C} \leftrightarrow \mathrm{G}: 0.8393, \mathrm{C} \leftrightarrow \mathrm{T}: 3.2696, \mathrm{G} \leftrightarrow \mathrm{T}: 1.0$ (fixed).

\subsection{Statistical analysis}

Data were analyzed using JMP 7.0.2 (SAS Institute Inc., USA). Time and treatment effects on development of cell density were analyzed using repeated measures analysis of variance (repeated measures ANOVA). Multivariate analysis of variance (MANOVA) was used for comparison of multiple treatment sets in case the assumptions of sphericity/compound symmetry for repeated measures ANOVA were not met. Normality of data at equally spaced time points were tested with the Shapiro-Wilk test and sphericity tested using Mauchly's Sphericity Test. For MANOVA tests, Pillai's trace test results and an epsilon-adjusted univariate F-test (Greenhouse-Geisser; G$\mathrm{G}$ ) for repeated measures ANOVA at a confidence level of 0.05 was chosen. In trials with unequal start cell densities between treatments, a survival rate (\% of initial density) instead of absolute cell density was used for analysis.

\section{Results}

\subsection{Incubation in basic media}

Freshly isolated Symbiodinium spp. were identified under the microscope as brownish coccoid cells in their vegetative state measuring $10.3 \pm 0.8 \mu \mathrm{m} \times 9.2 \pm 0.7 \mu \mathrm{m}$ (mean $\pm S D$, based on 2-D ellipsoid shape, $\mathrm{n}=50$ ). Both, incubation in basic media under active and passive aeration as well as half- and full-concentrated media under active aeration led to a rapid decline densities within three to ten days and the subsequent death of the culture (data not shown). Bleached cells as well as aggregates of Symbiodinium spp. cells in mucous matrices appeared within the first days of incubation. A number of other microalgae such as diatoms (e.g., Chaetoceros sp.), other dinoflagellates (e.g., Amphidinium sp.) or chlorophytes (e.g., Tetraselmis sp.) increased in number in all media except for the ASP-8A-medium. Ciliates, Heliozoa and green and red filamentous algae growing on the bottom of the flasks were also observed. Medium pH increased from initial values of $8.0 \pm 0.1$ to $8.2-8.4$ under active aeration and 8.69.2 under passive aeration for the incubation period of ten days. Cultures in ASP-8A-medium however had unexpectedly low $\mathrm{pH}$ values, around 6.9., reflecting a shift in the $\mathrm{pH}$ of the stock solution from 8.0 to 6.9 post preparation. Attempts to minimize growth of competing microalgae using serial dilutions in 96-well culture tissue plates had no effect on the survival of Symbiodinium spp. cells. While some wells showed moving flagellates at the end of the experiment, none of them could be identified as Symbiodinium spp. Similarly no cell proliferation or colony formation could be observed after a month of incubation on agar plates, regardless of medium. Microscopic examination revealed bleached cells on the agar surface. Repetition of basic media trials with higher initial densities under active aeration as half- and full-concentrated media led to similar results. Densities of Symbiodinium spp. declined rapidly within six days of observation, while $\mathrm{pH}$ stabilized around 8.3-8.4 and similar phytoplankton species as in the first trial emerged. Some of the cultures were further incubated without monitoring. After 45 days of incubation, one replicate of the half-concentrated L1- and the f/2-medium culture showed a mixed culture of motile Symbiodinium spp. and Amphidinium sp. cells. Symbiodinium spp. was successfully purified from the halfconcentrated $\mathrm{f} / 2$-medium culture by a combination of single cell picking under the microscope and growth on agar plates with subsequent colony picking. The obtained culture HI-0509 was genotyped as outlined earlier.

\subsection{Incubation in supplemented media and modified ASP-8A-medium}

Trials involving undefined supplements and glycerol supplements (Table 1 ) led to similar results as basic media trials. Densities dropped to non-detectable levels within five and six days of observation with increasing appearance of bleached Symbiodinium spp. cells, cell agglomerates and growth of other microalgae. With respect to glycerol supplements, a considerable proliferation of Heliozoa with visible axopods could be observed in K-medium cultures. Additionally, bacterial contamination developed in these media, despite the initial antibiotic treatment of the Symbiodinium spp. isolate. Symbiodinium spp. cells in their motile thecate stage emerged in one replicate of L1medium ( $+50 \mathrm{mM}$ glycerol) after 21 days. These cells were purified and the subsequent culture HI-0609 genotyped.

In contrast to previous trials, incubation in amino acid plus taurine supplemented L1-, f/2- and K-medium indicated a stabilizing effect on densities of freshly isolated Symbiodinium spp. cells from P. compressa for at least 14 days. In a preliminary experiment, densities stabilized over 12 days in $\mathrm{f} / 2$ - and L1-medium after an initial decline on day three. A slight change in color of Symbiodinium spp. towards a more greenish appearance under the microscope could be observed in all media on day six. The apparent stabilizing effect was confirmed in a second experiment with an additional $24 \mathrm{~h}$ antibiotic treatment to reduce bacterial contamination (Fig. 1). Cell densities showed no apparent trend in all three media. Nevertheless, statistical analysis detected a significant time effect (MANOVA, F-value $=33,900.00$, d.f. $=6.1, p=0.0102$ ), which was the same for all media, i.e. there was neither a significant treatment effect nor a significant time-treatment interaction. All trials involving this complex organic supplement suffered from considerable bacterial contamination, regardless of initial antibiotic treatment. Throughout all experiments with amino acids plus taurine supplements, no motile Symbiodinium spp. cells were observed. All cells remained in their coccoid non-motile stage. Incubation experiments using diluted raw homogenate from the host $P$. compressa as supplement in basic media or SSW similarly

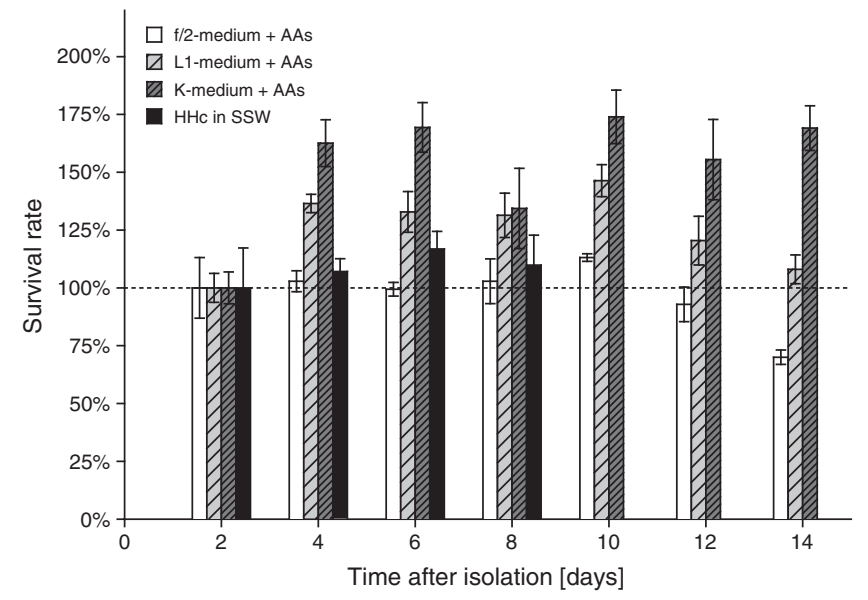

Fig. 1. Symbiodinium $\mathrm{C} 15$ survival rates over incubation time for amino acid plus taurine supplemented media (+AAs) and host homogenate in synthetic seawater ( $\mathrm{HHc}$ in SSW). Each bar represents mean $\pm \operatorname{SEM}(n=3)$. Due to ciliate grazing within the first two days of incubation, survival rates were based on mean densities on day 2 (dashed line indicates 100\% reference level). Cultures were maintained at light levels of $120-130 \mu \mathrm{mol} \mathrm{m}{ }^{-2} \mathrm{~s}^{-1}$ and $25^{\circ} \mathrm{C}$. 
indicated a temporarily stabilizing effect in some experiments. For example, densities in SSW supplemented with centrifuged raw homogenate supernatant stabilized densities for eight days, showing no significant trend (repeated measures ANOVA) (Fig. 1). On the other hand, filter-sterilized host homogenate at a concentration of $5.8 \pm 0.4 \mu \mathrm{g} / \mathrm{mL}$ total soluble protein (TSP) in L1-medium was unsuccessful over the same period of time. Densities increased slightly within the first two days $(\mu=0.08 \pm 0.04$, mean $\pm S D, n=3$ ), declined however from initially $95,000 \pm 6760$ cells $/ \mathrm{mL}$ (mean $\pm S D, n=3$ ) to approximately 10,000 cells/mL over the following ten days of incubation (data not shown).

Interestingly, one experiment stimulated a considerable growth response, using raw host homogenate in SSW. Densities increased from initially $85,347 \pm 5251$ cells $/ \mathrm{mL}$ to $317,604 \pm 42,964$ cells $/ \mathrm{mL}$ on day 12 (mean $\pm S D, n=6$ ). Development of cell densities in one monitored replicate depicted a significant negative quadratic regres$\operatorname{sion}\left(R^{2}=0.97, F_{2,2}=37.531, P=0.026\right)$, with a maximum cell density of $373,750 \pm 21,421$ cells $/ \mathrm{mL}$ on day 6 . Thus, initial growth between day 0 and day 3 of $0.36 \pm 0.05$ day $^{-1}$ declined linearly $\left(\mathrm{R}^{2}=0.98\right)$ over the following nine days. After pooling all six replicates on day 13 and transferring them into fresh host homogenate supplemented f/2-, L1- and K-medium, densities continued to significantly decrease over time (MANOVA, $F=109.07$, d.f. $=5.2$, $\mathrm{p}<0.0226$ ) with no significant medium effect or medium-time interaction (data not shown).

Agar plates supplemented with filtered or untreated raw host homogenate in L1-medium or SSW did not develop any visible Symbiodinium colonies in either of the plate types. Examination at the end of the incubation period revealed bleached and occasionally deformed cells. The majority of the cells were solitary (both plate types) and showed no signs of cell division.

Modification of the basic ASP-8A-medium to mimic the internal ionic milieu of the cytoplasm of a zooxanthellate anemone had no beneficial effect on survival rates of Symbiodinium spp. from $P$. compressa. Overall, mean cell densities in BSA-supplemented and pure modified ASP-8A-medium significantly declined over eight days of observation to $9-11 \%$ of the initial value (MANOVA, Fvalue $=276.52$, d.f. $=4.5, \mathrm{p}<0.0001$ ) without any significant medium difference or time-medium interaction (data not shown). The same observation was made for host homogenate supplemented ASP$8 \mathrm{~A}_{\text {mod }}$ despite the slower decline in densities. Over eight days of observation, mean density dropped to $65 \% \pm 12 \%$ (mean $\pm S D, n=3$ ) of initial density (data not shown).

\subsection{Genotyping and phylogenetic analysis}

Freshly isolated Symbiodinium cells were identified as Symbiodinium C15. The retrieved cultures of the incubation trials, HI-0509 and HI-0609, were identified as members of clade A. Phylogenetic analysis revealed genetic equality between both cultures and indicated close relationship to a free-living Symbiodinium population from Okinawa and a strain from Hawai'i (Fig. 2). High bootstrap support (99\%) indicated that the difference between this cultured strain and the Okinawan samples (Oku05, Oku09, Oku11, Oku12 and Oku17) was smaller compared to the Hawaiian strain HA3-5. Furthermore, the tree topology shows a divergence (100\% bootstrap support), which separates previously sequenced symbiotic A strains from the free-living Symbiodinium A strain detected in this study. The culture HI-0509 proved to be viable and is to date maintained in culture for future research.

\section{Discussion}

This study aimed to establish a viable, proliferating culture of a non-ancestral member of the Symbiodinium C clade from the Hawaiian endemic coral host $P$. compressa using a number of basic and modified culture media. Though no sustainable culture was established, the data indicate that organic supplements that are host-derived or mimic certain host features can be beneficial for in vitro survival of Symbiodinium C15 isolates. The experiments further suggest that this strain is incapable of surviving in basic media or seawater.

Early cultivation attempts of Symbiodinium isolates from a variety of hosts were successful using media with a number of organic additives (McLaughlin and Zahl, 1959). However, comparable growth rates have since been obtained in less complex media such as ASP 2 , ASP 6, ES-1 or basic Erd-Schreiber media (Morrill and Loeblich III, 1979; Taylor, 1975). As a result Symbiodinium cultures today are commonly maintained in f/2-, K-, L1-, ASP-8A- or IMK-medium. For the

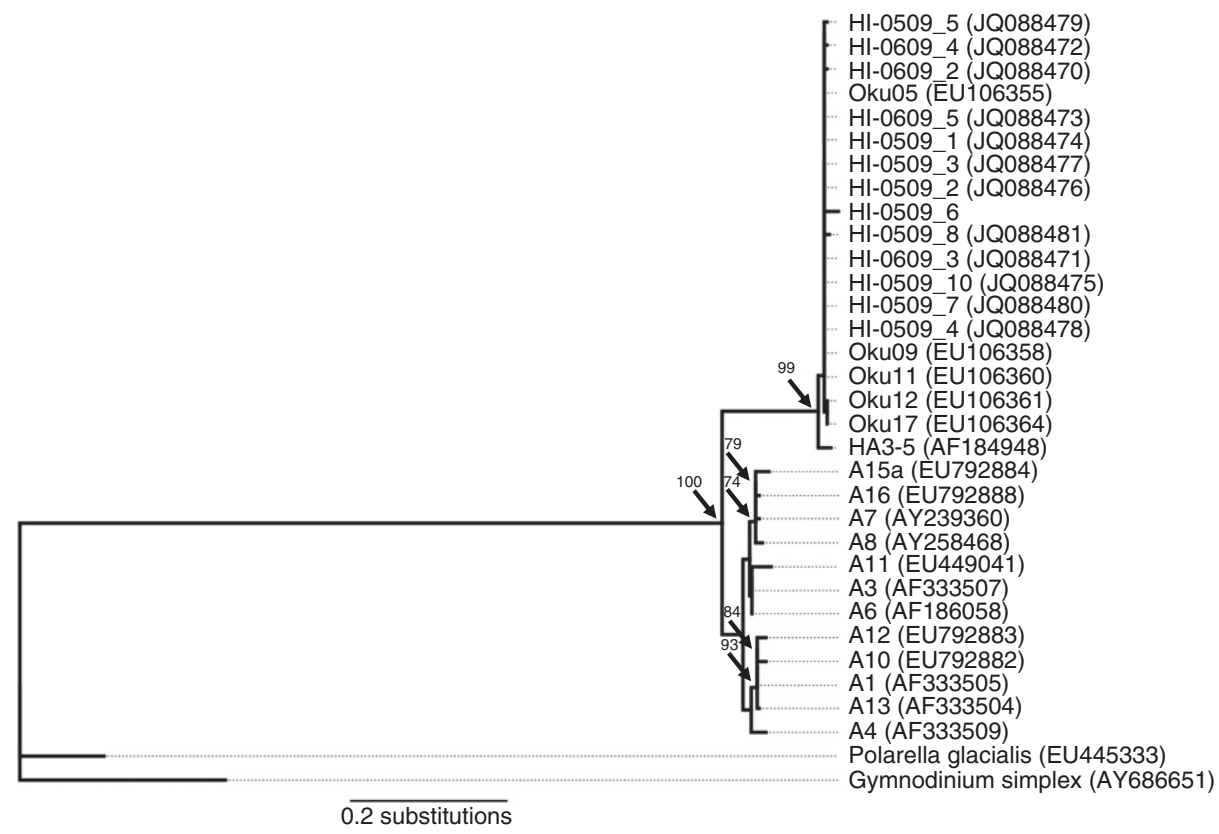

Fig. 2. ITS2 phylogeny of free-living and symbiotic Symbiodinium A clade samples inferred from maximum likelihood analysis with Polarella glacialis and Gymnodinium simplex as out-group. Symbiodinium A1 to A16 sequences from symbiotic strains, Oku-sequences and HA3-5 sequence derived from environmental Symbiodinium samples, HI-0509 and HI0609 sequences represent individually sequenced clones from this study. Bootstrap percentages of $>70 \%$ are indicated on nodes (Hillis and Bull, 1993). 
cultivation of Symbiodinium C15 however four of these media proofed to be unsuitable and led to a collapse in cell densities within ten to twelve days. As a result, we were unable to assess the suitability of certain media features over others (e.g., ammonium versus nitrate source). Past studies have shown that media containing environmental additives (Erd-Schreiber media) as well as defined organic supplements such as glycerol, glycolate, acetate, malate or propionate can enhance growth performance of certain Symbiodinium strains and other phytoplankton species (Cheng and Antia, 1970; Morrill and Loeblich III, 1979; Steen, 1987). Even though the idea of providing features similar to the natural habitat of free-living strains might support growth for some strains (see Taylor, 1975) and might provide localized nutrient benefits, neither Erd-Schreiber media nor glycerol supplements proved successful for the cultivation of Symbiodinium C15.

In contrast, media that contained free amino acids and taurine significantly enhanced the survival of freshly isolated Symbiodinium C15 cells. A synthetic cocktail representing the free amino acid pool measured in the coral P. damicornis (Gates et al., 1995), temporarily stabilized in vitro cultures of $P$. compressa symbionts. Incubation with host specific free amino acid cocktails (including the sulfonic acid taurine) in micro- to millimolar range can have a stimulating effect on fixation or release of carbon (Biel et al., 2007; Cook and Davy, 2001; Gates et al., 1995; Stat et al., 2008b; Wang and Douglas, 1997). While the general alleviating effect on physiological parameters of freshly isolated symbionts has been clearly demonstrated, its effect size is clade dependent (Gates et al., 1999; Stat et al., 2008b). The prevention of an immediate cell death after isolation as result of this additive in our study might indicate a temporary (or permanent) dependency on an external amino acid supply as a result of a limited synthesis capability after isolation for Symbiodinium C15.

Similar to the theory of symbiont regulation by nitrogen limitation in corals (Falkowski et al., 1993), uptake of amino acids by symbionts as primary source of nitrogen has been postulated for the symbiotic Hydra-Chlorella system (McAuley, 1986). Earlier studies illustrated higher uptake rates and smaller intracellular pools for certain amino acids in freshly isolated Chlorella sp. symbionts, compared to cultured strains, as well as growth capability on a wide range of organic natural and synthetic nitrogen compounds as sole nitrogen source (Le Den Dooren, 1967; McAuley, 1986, 1987). Uptake of amino acids such as methionine, cysteine, alanine and taurine by Symbiodinium has also been demonstrated for in vitro (Carroll and Blanquet, 1984; Deane and O'Brien, 1981) and possibly for in hospite cells (Cook, 1971; Steen, 1986). Similar to the Hydra-Chlorella system, uptake of taurine, cysteine and methionine is more efficient in symbiotic vs. cultured Symbiodinium cells, with some indication for an inducible uptake system that increases the substrate affinity at low taurine concentrations (Deane and O'Brien, 1981; Wang and Douglas, 1997). Especially with respect to the component taurine and the speculation of Wang and Douglas (1997) about its potential involvement as host factor, it is noteworthy that $P$. compressa exhibits a 10 -fold higher dimethyltaurine concentration, compared to the taurine levels of our synthetic supplement derived from P. damicornis (Yancey et al., 2010).

There is ample evidence that host homogenate can stimulate release of photosynthetic products from symbiotic algae of giant clams, anemones, zoanthids and corals (Cook and Davy, 2001; Gates et al., 1995; Grant et al., 1997; Ishikura et al., 2004; Sutton and Hoegh-Guldberg, 1990; Trench, 1971). While a beneficial effect appears to be only valid for symbiotic and not for aposymbiotic hosts (Trench, 1971), there is also evidence for adverse effects of certain host homogenates (e.g., Sutton and Hoegh-Guldberg, 1990). Host derived homogenate in synthetic seawater stabilized cell densities of freshly isolated Symbiodinium C15 cells over six to eight days and stimulated considerable proliferation in one of our trials. Yet no readily proliferating culture could be obtained even after transfer of these cells into supplemented basic media. Interestingly, neither stable or proliferating Symbiodinium C15 cultures developed motile cells. Coral specific factors in the host homogenate might have suppressed the development of motility, while permitting cell division, as this would be the case in hospite. The involvement of coral specific lectins like SLL-2 from Sinularia lochmodes in regulation of motility has been shown by Koike et al. (2004). A major problem with host derived supplements remains however the quantity and/or quality of the supplement. While protein concentration can be used as a measure of quantity, overall values do not necessarily account for changes in the potentially important peptide or free amino acid content. Since we observed a similar positive effect on cell survival between synthetic and natural host factor for Symbiodinium C15, the responsible compounds might indeed involve a set of free amino acids as suggested by some authors (Gates et al., 1995; Stat et al., 2008b). Host homogenate dependency has also been observed for a Symbiodinium C2 strain isolated from Tridacna crocea (Ishikura et al., 2004). While the $\mathrm{C} 2$ strain proved to be viable but slow-growing in basic $\mathrm{f} / 2$ - and IMK-medium, its long-term maintenance required the addition of host homogenate, since without it, growth rates decreased and the strain died (T. Maruyama, personal communication). These authors managed to raise a colony of this strain after 6 months on agar containing host homogenate at a TSP concentration of $10 \mu \mathrm{g} / \mathrm{mL}$. In our study however, all incubations on agar plates proved to be unsuccessful, despite different host homogenate concentrations and treatments.

While differential cultivation success of Symbiodinium isolates is a well known fact, there seems to be a general difficulty to establish representative cultures in case of $\mathrm{C}$ clade isolates from corals. For example, Rogers and Davis (2006) cultured the ITS2 types B1 and A2 from the corals Montipora verrucosa and P. damicornis from Kāne'ohe Bay, Hawai'i, although the dominant types in both corals for this region belong to clade C (LaJeunesse, 2005; LaJeunesse et al., 2004). The A clade strain that we isolated in our study further illustrates the problem of differential cultivation. Its genetic identity suggests it came as contamination with the Porites specimen, since it has not been detected in P. compressa from Hawai'i to date. That and the fact that it was only detected after prolonged incubation, indicate that the initial population size must have been very small. The observed similarity between Hawaiian and Okinawan Symbiodinium sequences (Fig. 2) from tropical sand samples suggests a direct link or a common source for these populations. Combining previous results with our study draws a picture connecting samples from Palau (Carlos et al., 1999), Okinawa (Hirose et al., 2008), Ogasawara Islands (Reimer et al., 2010) and Hawai'i (Carlos et al., 1999, this study) that shows free-living clade A members with high ITS2 sequence similarity that group distinctly separate from endosymbiotic clade A sequence types.

Almost all corals that have been found to contain Symbiodinium C15 transfer their symbionts vertically, which means acquisition by maternal inheritance (Hirose et al., 2001; Richmond and Hunter, 1990). A vertical transmission mode links evolutionary fitness of the symbiont to growth and reproductive output of the host, whereas vertical transmission favors the potential for symbiont virulence under certain conditions (e.g., Sachs and Wilcox, 2006). In the parasitism-mutualism continuum, the evolution of reduced antagonism in a long-term interaction between two partners is assumed to be dependent on high partner fidelity and low availability of alternative partners. Genetic alteration in the symbiont that results in loss of a horizontal transmission in combination with the evolution of endosymbiont containing offspring on the host side would increase the persistence of this relationship (Ewald, 1987). Our studies showed that despite temporary survival and proliferation after isolation, Symbiodinium C15 did not develop any motility. Furthermore neither basic media nor seawater promotes the survival of this strain. Both observations raise the question whether this strain can survive ex hospite under natural conditions. While release of Symbiodinium 
cells from corals is evident, a number of studies support the presence and survival of Symbiodinium spp. in the water column (e.g., Coffroth et al., 2006; Porto et al., 2008; Thornhill et al., 2006). However, sampling in Kāne'ohe Bay has not detected the presence of C15 cells in the water column in a reef that exhibits approximately $90 \% P$. compressa cover over the last five decades. To our knowledge, the study of Venera-Ponton et al. (2010) is the only consistent study that found C15 outside of a host, associated with the macroalgae Hypnea panose at Heron Island, GBR.

The results of this cultivation study point to the following conclusion: Symbiodinium C15 does not survive in a basic seawater environment for extended periods of time unless a host-derived or potential host mimicking feature is present. Also, isolated C15 cells apparently lack the ability to develop motility, which might be host-induced (in case of host homogenate supplements) or might represent a genetic alteration of the symbiont as consequence of its vertical transmission mode and the temporal longevity and coevolution with the host. Consequently, post-bleaching recovery of hosts that solely harbor C15 symbionts would depend on the proliferation and re-colonization of the remaining endosymbiotic population. The apparent dependence of $\mathrm{C} 15$ on host-like conditions suggests that specific life history features of the holobiont may contextualize the difficulties we encountered here in obtaining a typical motile, readily proliferating Symbiodinium culture. In the broader context, it might suggest a connection between vertical transmission mode, host dependency and bleaching resistance of this association as result of evolutionary co-adaptation between $P$. compressa and C15 symbionts. Our study also provides compelling evidence supporting the use of host mimics or host derived supplements to study otherwise 'unculturable' Symbiodinium strains.

\section{Acknowledgments}

The authors would like to thank R.A. Kinzie III for helpful comments on the culture work. Coral samples were collected under the Special Activity Permit (SAP) 2008-99 and 2009-101 of the Department of Land \& Natural Resources, State of Hawai'i. This work was supported by NSF (OCE-0752604 to RDG and OIA-0554657 administered by University of Hawai'i). Thanks also go to HIMB and the Rosa Luxemburg Foundation for allowing TK to complete this work as a visiting scholar in 2009. This paper represents HIMB contribution number 1479 and SOEST contribution number 8530.[SS]

\section{References}

Andersen, R.A., Berges, J.A., Harrison, P.J., Watanabe, M.M., 2005. Recipes for freshwater and seawater media. In: Andersen, R.A. (Ed.), Algal Culturing Techniques. Elsevier Academic Press, Amsterdam, pp. 429-538.

Barshis, D.J., Stillman, J.H., Gates, R.D., Toonen, R.J., Smith, L.W., Birkeland, C., 2010. Protein expression and genetic structure of the coral Porites lobata in an environmentally extreme Samoan back reef: does host genotype limit phenotypic plasticity? Mol. Ecol. 19, 1705-1720.

Biel, K.Y., Gates, R.D., Muscatine, L., 2007. Effects of free amino acids on the photosynthetic carbon metabolism of symbiotic dinoflagellates. Russ. J. Plant Physiol. 54, $171-183$

Blank, R.J., 1987. Cell architecture of the dinoflagellate Symbiodinium sp. inhabiting the Hawaiian stony coral Montipora verrucosa. Mar. Biol. 94, 143-155.

Bradford, M.M., 1976. A rapid and sensitive method for the quantitation of microgram quantities of protein utilizing the principle of protein-dye binding. Anal. Biochem. 72, 248-254.

Carlos, A.A., Baillie, B.K., Kawachi, M., Maruyama, T., 1999. Phylogenetic position of Symbiodinium (Dinophyceae) isolates from Tridacnids (Bivalvia), Cardiids (Bivalvia), a sponge (Porifera), a soft coral (Anthozoa), and a free-living strain. J. Phycol. 35, 1054-1062.

Carroll, S., Blanquet, R.S., 1984. Alanine uptake by isolated zooxanthellae of the mangrove jellyfish, Cassiopea xamachana. I. Transport mechanisms and utilization. Biol. Bull. 166, 409-418.

Cheng, J.Y., Antia, N.J., 1970. Enhancement by glycerol of phototrophic growth of marine planktonic algae and its significance to the ecology of glycerol pollution. J. Fish. Res. Board Can. 27, 335-346.

Coffroth, M.A., Santos, S.R., 2005. Genetic diversity of symbiotic dinoflagellates in the genus Symbiodinium. Protist 156, 19-34.
Coffroth, M.A., Lewis, C.F., Santos, S.R., Weaver, J.L., 2006. Environmental populations of symbiotic dinoflagellates in the genus Symbiodinium can initiate symbioses with reef Cnidarians. Curr. Biol. 16, 985-987.

Cook, C.B., 1971. Transfer of ${ }^{35}$ S-labelled material from Aiptasia sp. to its endosymbiotic zooxanthellae. In: Lenhoff, H., Muscatine, L., Davis, L.V. (Eds.), Experimental Coelenterate Biology. University of Hawai'i Press, Honolulu, pp. 218-224.

Cook, C.B., Davy, S.K., 2001. Are free amino acids responsible for the 'host factor' effects on symbiotic zooxanthellae in extracts of host tissue? Hydrobiologia 461, 71-78.

Correa, A.M.S., Baker, A.C., 2009. Understanding diversity in coral-algal symbiosis: a cluster-based approach to interpreting fine-scale genetic variation in the genus Symbiodinium. Coral Reefs 28, 81-93.

Deane, E.M., O'Brien, R.W., 1981. Uptake of sulphate, taurine, cysteine and methionine by symbiotic and free-living dinoflagellates. Arch. Microbiol. 128, 311-319.

Ewald, P.W., 1987. Transmission modes and evolution of the parasitism-mutualism continuum. Ann. N. Y. Acad. Sci. 503, 295-306.

Falkowski, P.G., Dubinsky, Z., Muscatine, L., McCloskey, L., 1993. Population control in symbiotic corals. Bioscience 43, 606-611.

Fisher, P. (2006). Investigating the photo-physiology of Symbiodinium sub-clades and its relationship to coral bleaching. PhD thesis. Brisbane: University of Queensland.

Fitt, W.K., Gates, R.D., Hoegh-Guldberg, O., Bythell, J.C., Jatkar, A., Grottoli, A.G., Gomez, M., Fisher, P., Lajeunesse, T.C., Pantos, O., et al., 2009. Response of two species of Indo-Pacific corals, Porites cylindrica and Stylophora pistillata, to short-term thermal stress: the host does matter in determining the tolerance of corals to bleaching. J. Exp. Mar. Biol. Ecol. 373, 102-110.

Freudenthal, H.D., 1962. Symbiodinium gen. nov. and Symbiodinium microadriaticum sp. nov., a zooxanthella: taxonomy, life cycle, and morphology. J. Protozool. 9, 45-52.

Gascuel, O., 1997. BIONJ: an improved version of the NJ algorithm based on a simple model of sequence data. Mol. Biol. Evol. 14, 685-695.

Gates, R.D., Hoegh-Guldberg, O., McFall-Ngai, M.J., Bil, K.Y., Muscatine, L., 1995. Free amino acids exhibit anthozoan "host factor" activity: they induce the release of photosynthate from symbiotic dinoflagellates in vitro. Proc. Natl. Acad. Sci. 92, 7430-7434.

Gates, R.D., Bil, K.Y., Muscatine, L., 1999. The influence of an anthozoan "host factor" on the physiology of a symbiotic dinoflagellate. J. Exp. Mar. Biol. Ecol. 232, 241-259.

Goulet, T.L., LaJeunesse, T.C., Fabricius, K.E., 2008a. Symbiont specificity and bleaching susceptibility among soft corals in the 1998 Great Barrier Reef mass coral bleaching event. Mar. Biol. 154, 795-804.

Goulet, T.L., Simmons, C., Goulet, D., 2008b. Worldwide biogeography of Symbiodinium in tropical octocorals. Mar. Ecol. Prog. Ser. 355, 45-48.

Grant, A.J., Rémond, M.R., People, J., Hinde, R., 1997. Effects of host-tissue homogenate of the scleractinian coral Plesiastrea versipora on glycerol metabolism in isolated symbiotic dinoflagellates. Mar. Biol. 128, 665-670.

Guindon, S., Gascuel, O., 2003. A simple, fast and accurate algorithm to estimate large phylogenies by maximum likelihood. Syst. Biol. 52, 696-704.

Hillis, D.M., Bull, J.J., 1993. An empirical test of bootstrapping as a method for assessing confidence in phylogenetic analysis. Syst. Biol. 42, 182-192.

Hirose, M., Kinzie III, R.A., Hidaka, M., 2001. Timing and process of entry of zooxanthellae into oocytes of hermatypic corals. Coral Reefs 20, 273-280.

Hirose, M., Reimer, J.D., Hidaka, M., Sunda, S., 2008. Phylogenetic analyses of potentially free-living Symbiodinium spp. isolated from coral reef sand in Okinawa, Japan. Mar. Biol. 155, 105-112.

Ishikura, M., Hagiwara, K., Takishita, K., Haga, M., Iwai, K., Maruyama, T., 2004. Isolation of new Symbiodinium strains from Tridacnid giant clam (Tridacna crocea) and sea slug (Pteraeolidia ianthina) using culture medium containing giant clam tissue homogenate. Marine Biotechnol. 6, 378-385.

Koike, K., Jimbo, M., Sakai, R., Kaeriyama, M., Muramoto, K., Ogata, T., Maruyama, T., K., $\mathrm{H} ., 2004$. Octocoral chemical signaling selects and controls dinoflagellate symbionts. Biol. Bull. 207, 80-86.

Lajeunesse, T.C., 2001. Investigating the biodiversity, ecology and phylogeny of endosymbiotic dinoflagellates in the genus Symbiodinium using the ITS region: in search of a "species" level marker. J. Phycol. 37, 866-880.

Lajeunesse, T.C., 2005. "Species" radiations of symbiotic dinoflagellates in the Atlantic and Indo-Pacific since the Miocene-Pliocene transition. Mol. Biol. Evol. 22, 570-581.

LaJeunesse, T.C., Thornhill, D.J., Cox, E.F., Stanton, F.G., Fitt, W.K., Schmidt, G.W., 2004. High diversity and host specificity observed among symbiotic dinoflagellates in reef coral communities from Hawaii. Coral Reefs 23, 596-603.

Lajeunesse, T.C., Bonilla, H.R., Warner, M.E., Wills, M., Schmidt, G.W., Fitt, W.K., 2008. Specificity and stability in high latitude eastern Pacific coral-algal symbioses. Limnol. Oceanogr. 53, 719-727.

Lajeunesse, T.C., Pettay, D.T., Sampayo, E.M., Phongsuwan, N., Brown, B., Obura, D.O., Hoegh Guldberg, O., Fitt, W.K., 2010. Long standing environmental conditions, geographic isolation and host-symbiont specificity influence the relative ecological dominance and genetic diversification of coral endosymbionts in the genus Symbiodinium. J. Biogeogr. 37, 785-800.

Le Den Dooren, D.E.J., 1967. Dark and light metabolism of amino acids in Chlorella vulgaris. J. Microbiol. Serol. 33, 166-170.

Loya, Y., Sakai, K., Yamazato, K., Nakano, Y., Sambali, H., van Woesik, R., 2001. Coral bleaching: the winners and the losers. Ecol. Lett. 4,122-131.

McAuley, P.J., 1986. Uptake of amino acids by cultured and freshly isolated symbiotic Chlorella. New Phytol. 104, 415-427.

McAuley, P.J., 1987. Nitrogen limitation and amino-acid metabolism of Chlorella symbiotic with green hydra. Planta 171, 532-538.

McLaughlin, J.J.A., Zahl, P.A., 1959. Axenic zooxanthellae from various invertebrate hosts. Ann. N.Y. Acad. Sci. 77, 55-72. 
Morrill, L.C., Loeblich III, A.R., 1979. An investigation of heterotrophic and photoheterotrophic capabilities in marine Pyrrhophyta. Phycologia 18, 394-404.

Muscatine, L., Hand, C., 1958. Direct evidence for the transfer of materials from symbiotic algae to the tissues of a Coelenterate. Proc. Natl. Acad. Sci. U. S. A. 44, 1259

Pochon, X., Gates, R.D., 2010. A new Symbiodinium clade (Dinophyceae) from soritid foraminifera in Hawai'i. Mol. Phylogenet. Evol. 56, 492-497.

Pochon, X., Montoya-Burgos, J.I., Stadelmann, B., Pawlowski, J., 2006. Molecular phylogeny, evolutionary rates, and divergence timing of the symbiotic dinoflagellate genus Symbiodinium. Mol. Phylogenet. Evol. 38, 20-30.

Polne-Fuller, M., 1991. A novel technique for preparation of axenic cultures of Symbiodinium through selective digestion by amoeba. J. Phycol. 27, 552-554

Porto, I., Granados, C., Restrepo, J.C., Sánchez, J.A., 2008. Macroalgal-associated dinoflagellates belonging to the genus Symbiodinium in Caribbean reefs. PLoS One 3 e2160.

Reimer, J.D., Shah, M.M.R., Sinniger, F., Yanagi, K., Suda, S., 2010. Preliminary analyses of cultured Symbiodinium isolated from sand in the oceanic Ogasawara Islands, Japan. Mar. Biodivers. 40, 237-247.

Richmond, R.H., Hunter, C.L., 1990. Reproduction and recruitment of corals: comparisons among Caribbean, the tropical Pacific, and the Red Sea. Mar. Ecol. Prog. Ser. 60, 185-203.

Rogers, J.E., Davis, R.H., 2006. Application of a new micro-culturing-technique to assess the effects of temperature and salinity on specific growth rates of six Symbiodinium isolates. Bull. Mar. Sci. 79, 113-126.

Sachs, J.L., Wilcox, T.P., 2006. A shift to parasitism in the jellyfish symbiont Symbiodinium microadriaticum. Proc. R. Soc. B 273, 425-429.

Santos, S.R., Taylor, D.J., Coffroth, M.A., 2001. Genetic comparisons of freshly isolated versus cultured symbiotic dinoflagellates: implications for extrapolating to the intact symbiosis. J. Phycol. 37, 900-912.

Seibt, C., Schlichter, D., 2001. Compatible intracellular ion composition of the host improves carbon assimilation by zooxanthellae in mutualistic symbioses. Naturwissenschaften 88, 382-386.

Stat, M., Carter, D., Hoegh-Guldberg, O., 2006. The evolutionary history of Symbiodinium and scleractinian hosts - Symbiosis, diversity, and the effect of climate change. Perspect. Plant Ecol. Evol. Syst. 8, 26-43.

Stat, M., Loh, W.K.W., Hoegh-Guldberg, O., Carter, D.A., 2008a. Symbiont acquisition strategy drives host-symbiont associations in the southern Great Barrier Reef. Coral Reefs 27, 763-772.
Stat, M., Morris, E., Gates, R.D., 2008b. Functional diversity in coral-dinoflagellate symbiosis. Proc. Natl. Acad. Sci. 105, 9256-9261.

Stat, M., Loh, W.K.W., Lajeunesse, T.C., Hoegh-Guldberg, O., Carter, D.A., 2009a. Stability of coral-endosymbiont associations during and after a thermal stress event in the southern Great Barrier Reef. Coral Reefs 28, 709-713.

Stat, M., Pochon, X., Cowie, R.O.M., Gates, R.D., 2009b. Specificity in communities of Symbiodinium in corals from Johnston Atoll. Mar. Ecol. Prog. Ser. 386, 83-96.

Steen, R.G., 1986. Evidence for heterotrophy by zooxanthellae in symbiosis with Aiptasia pulchella. Biol. Bull. 170, 267-278.

Steen, R.G., 1987. Evidence for facultative heterotrophy in cultured zooxanthellae. Mar. Biol. 95, 15-23.

Stimson, J., Sakai, K., Sembali, H., 2002. Interspecific comparison of the symbiotic relationship in corals with high and low rates of bleaching-induced mortality. Coral Reefs 21, 409-421.

Sutton, D.C., Hoegh-Guldberg, O., 1990. Host-zooxanthella interactions in four temperate marine invertebrate symbioses: assessment of effect of host extracts on symbionts. Biol. Bull. 178, 175-186.

Taylor, D.L., 1975. Symbiotic dinoflagellates. Symp. Soc. Exp. Biol. 29, 267-277.

Thornhill, D.J., Daniel, M.W., Lajeunesse, T.C., Schmidt, G.W., Fitt, W.K., 2006. Natural infections of aposymbiotic Cassiopea xamachana scyphistomae from environmental pools of Symbiodinium. J. Exp. Mar. Biol. Ecol. 338, 50-56.

Trench, R.K., 1971. The physiology and biochemistry of zooxanthellae symbiotic with marine coelenterates. III. The effect of homogenates of host tissues on the excretion of photosynthetic products in vitro by zooxanthellae from two marine coelenterates. Proc. R. Soc. Lond. B Biol. Sci. 177, 251-264.

Venera-Ponton, D.E., Diaz-Pulido, G., Rodriguez-Lanetty, M., Hoegh-Guldberg, O., 2010. Presence of Symbiodinium spp. in macroalgal microhabitats from the southern Great Barrier Reef. Coral Reefs 29, 1-12.

Visram, S., Douglas, A.E., 2006. Molecular diversity of symbiotic algae (Zooxanthellae) in scleractinian corals of Kenya. Coral Reefs 25, 172-176.

Wang, J.-T., Douglas, A.E., 1997. Nutrients, signals, and photosynthate release by symbiotic algae. Plant Physiol. 114, 631-663.

Yancey, P.H., Heppenstall, M., Ly, S., Andrell, R.M., Gates, R.D., Carter, V.L., Hagedorn, M., 2010. Betaines and dimethylsulfoniopropionate as major osmolytes in Cnidaria with endosymbiotic dinoflagellates. Physiol. Biochem. Zool. 83, 167-173. 